\title{
High incidence of scintigraphic myocardial uptake defects at rest and during exercise in male elite
}

\section{runners}

Frederic Bouvier, Mohsen Nejat, Bo Berglund, Lars-Åke Brodin, Lennart Jorfeldt, Anders Juhlin-Dannfelt, Bengt Saltin, Mats Jensen-Urstad

\begin{abstract}
Objective-To evaluate the usefulness of myocardial perfusion scintigraphy (MIBI-SPECT) as a diagnostic tool in well trained men.

Design-The study was prospective, involving 2 d stress-rest myocardial scintigraphy (MIBI-SPECT), polar map reconstruction with and without uniform attenuation correction, and comparison with a healthy male group (local Swedish) and with a commonly used reference group (American, Emory University Hospital).

Setting-University Hospital, Stockholm, Sweden.

Subjects-16 healthy, male elite runners (mean (SD) age 26.1 (3.1) years). Peak oxygen uptake 73 (4) $\mathrm{ml} \mathrm{O} / \mathrm{kg} / \mathrm{min}$.

Results-Uptake defects on polar maps were found in the majority of the runners compared with both reference groups (local Swedish 13/16, American 10/16). Most defects (91\%) were fixed. Defects were located in the anterior, lateral, and posterior regions of the left ventricle. Application of a uniform attenuation correction algorithm enhanced rather than reduced perfusion defect size, probably because this correction method is imperfect in SPECT studies of the thoracic cavity.

Conclusions-If myocardial perfusion scintigraphy is used for evaluating well trained men, existing normal reference files for semiquantitative evaluation appear to be inadequate.
\end{abstract}

South Hospital, Stockholm, Sweden: Department of Clinical Physiology F Bouvier M Nejat

Karolinska Hospital, Stockholm, Sweden: Department of Internal Medicine

B Berglund

Department of Thoracic Physiology

L Jorfeldt

A Juhlin-Dannfelt

Department of

Physiology and

Pharmacology

B Saltin

Huddinge University Hospital, Huddinge, Sweden: Department of Cardiology

$M$ Jensen-Urstad

L-Â Brodin

Correspondence to: Dr F Bouvier, Department of Clinical Physiology, South

Hospital, S-118 83

Stockholm, Sweden.

Accepted for publication

21 November 1996
(Heart 1997;77:252-255)

Keywords: myocardial scintigraphy; SPECT; echocardiography; physical training

Ischaemic heart disease is a growing problem in younger patient categories ( $<40$ years), especially men. Even among young athletes ischaemic heart disease is a reality, causing $14 \%$ of all sudden deaths among athletes less than 30 years old, ${ }^{1}$ and it is the dominant cause of sudden death in older athletes. ${ }^{2}$ Among athletes under 30, hypertrophic cardiomyopathy, myocarditis, arrhythmogenic right ventricular dysplasia (ARVD), and coronary vessel abnormalities are the major causes of sudden death. ${ }^{1}$

Myocardial perfusion scintigraphy with single photon emission tomography technique
(SPECT) is a valuable diagnostic and prognostic tool in patients with suspected or $\frac{\sigma}{\vec{D}}$ known ischaemic heart disease. ${ }^{3}$ The introduc- $\unrhd$ tion of semiquantitative measurements of isotope uptake in the myocardium and $\overrightarrow{0}$ comparative studies with polar maps from healthy reference groups has increased the $\vec{\omega}$ diagnostic power of cardiac SPECT and has made it less prone to subjective influences. SPECT measures relative myocardial blood $خ$ flow and can also measure blood flow distur- $\omega$ bances in the myocardium from causes other $N$ than coronary arteriosclerosis. Cardiac SPECT 응 using thallium-201 or technetium-99m (Tc$99 \mathrm{~m})$ sestamibi can detect hibernating 3 myocardium, which is severely hypoperfused and functionally impaired but metabolically $\stackrel{5}{\mathcal{S}}$ viable and will improve functionally after $\vec{\theta}$ revascularisation.

Several studies have shown scintigraphic perfusion defects in patients with angina pectoris and angiographically normal coronary arteries (syndrome $\mathrm{X}$ ) and in patients with hypertrophic cardiomyopathy. ${ }^{4-7}$ Post myo- $\mathbb{D}$ carditic changes such as fibrotic areas can also

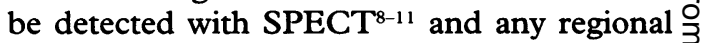
blood flow disturbances during acute myocarditis ought to be detectable.

SPECT thus has the potential of becoming an important tool in evaluating young trained patients with suspected heart disease. However, existing reference populations for semi- $\frac{3}{3}$ quantitative (polar map) evaluation of myocardial scintigraphic studies consist $\frac{3}{3}$ mainly of older and relatively untrained men 0 and women. Relative distribution of isotope in the myocardium may be different in young $\frac{7}{0}$ well trained persons compared to older and
relatively untrained individuals.

We have therefore performed maximum $N$ exercise stress and rest scintigraphy in a group N of healthy male elite runners and compared semiquantitative scintigraphic data with a local ${ }_{0}^{2}$ Swedish male reference group and a com- $\frac{\bar{D}}{\varnothing}$ monly used American (Emory University Hospital) reference group. ${ }^{12}$

\section{Methods}

SUBJECTS

Sixteen healthy male middle and long distance runners competing at national or international응 level and a reference group of 11 sedentary or moderately physically active men (local Swedish) were studied. The pretest probability for cardiac disease in either group based on Bayesian principles was less than $5 \% .{ }^{13}$ None of the subjects had any history of cardiac dis- 
Table 1 Physical characteristics

\begin{tabular}{|c|c|c|c|c|}
\hline & \multicolumn{2}{|c|}{ Runners, $n=16$} & \multicolumn{2}{|c|}{ Male controls (Swedish), $n=11$} \\
\hline & Mean $(S D)$ & Range & Mean (SD) & Range \\
\hline $\begin{array}{l}\text { Age (years) } \\
\text { Height }(\mathrm{cm}) \\
\text { Weight }(\mathrm{kg}) \\
\text { Peak heart rate (beats } / \mathrm{min}) \\
\text { Peak } \mathrm{VO}_{2}(\mathrm{ml} / \mathrm{kg} / \mathrm{min}) \\
\text { BMI }\left(\mathrm{kg} / \mathrm{m}^{2}\right)\end{array}$ & $\begin{array}{l}26 \cdot 1(3 \cdot 1) \\
178(6 \cdot 3) \\
65 \cdot 2(4 \cdot 2) \\
181(8) \\
73 \cdot 0(4 \cdot 0) \\
20 \cdot 5(0 \cdot 6)\end{array}$ & $\begin{array}{l}22 \text { to } 33 \\
169 \text { to } 187 \\
56 \text { to } 73 \\
158 \text { to } 197 \\
68 \cdot 1 \text { to } 84 \cdot 9 \\
19 \cdot 3 \text { to } 21 \cdot 5\end{array}$ & $\begin{array}{l}42.5(7 \cdot 1)(P<0.01) \\
179(4 \cdot 8)(\mathrm{NS}) \\
80.2(11.4)(\mathrm{P}<0.01) \\
167(11) \\
25.1(3.7)(P<0.01)\end{array}$ & $\begin{array}{l}27 \text { to } 49 \\
174 \text { to } 187 \\
60 \text { to } 100 \\
149 \text { to } 187 \\
18 \cdot 5 \text { to } 32 \cdot 3\end{array}$ \\
\hline
\end{tabular}

VัO ${ }_{2}$, oxygen consumption; $\mathrm{BMI}$, body mass index.

ease. Data on age, body dimensions, and peak pulmonary oxygen uptake (measured on treadmill with Douglas bag technique two weeks before scintigraphy) are presented in table 1. Pathological myocardial hypertrophy or valve disorders were excluded by echocardiography (table 2). The subjects were informed of the possible risks before they gave their consent to the studies. The experimental protocol was approved by the institutional ethics committee.

\section{INVESTIGATIONS}

All subjects underwent graded bicycle ergometry in the sitting position, starting at 110 and $60 \mathrm{~W}$ for the athletes and the control group, respectively, with a $20 \mathrm{~W}$ increase every minute until exhaustion. A 12 channel ECG was continuously recorded. At the end of exercise $500 \mathrm{MBq}$ Tc-99m sestamibi (Cardiolite, Du Pont, Massachusetts, USA) was injected into an antecubital vein. Exercise was continued at least 90 seconds after injection. For resting studies, subjects were injected with 700 $\mathrm{MBq}$ Tc-99m sestamibi; the interval between resting and exercise studies was $\geqslant 24$ hours. Stress and rest data were acquired 60 minutes after injection of Tc-99m sestamibi. To minimise gall bladder activity, all subjects consumed a light fatty meal between the Tc-99m sestamibi injection and imaging. Data were acquired on a gamma camera (XT/C, General Electric, Milwaukee, Wisconsin, USA) linked to a General Electric Star 3200 computer. A general purpose collimator was used and a $20 \%$ energy window was centred over the $140 \mathrm{keV}$ photo peak. Projection data were collected at 32 angles over a semicircular $180^{\circ}$ orbit $\left(45^{\circ}\right.$ right anterior oblique to $45^{\circ}$ left posterior oblique) and stored in $64 \times 64$ matrices. Acquisition time was 30 seconds per projection for both stress and rest studies. Semiquantitative evaluation was done using the local Swedish reference group and the American male (Emory University Hospital) reference group. ${ }^{12}$ Evaluation was made by polar plots. Clustered defects on the polar map of $>10$ pixels and $>2.5 \mathrm{SD} /$ pixel were considered as significant. Reconstruction of the polar maps was performed with and without attenuation correction according to Chang's method. ${ }^{14}$

Echocardiographic measurements on the runners (14 subjects, two analyses lost due to technical problems) were acquired from standard projections (parasternal and apical positions) with the subjects in the left lateral decubitus position using an Acuson XP 128 and a $2.5 \mathrm{MHz}$ transducer. Measurements were done from cross sectional guided $M$ mode registrations and with pulsed Doppler.

\section{STATISTICAL ANALYSIS}

All data are expressed as mean (SD). Student's unpaired and paired $t$ test was used when appropriate. A $P$ value of $<0.05$ was considered significant.

\section{Results}

Body mass index (BMI) differed significantly between runners and the local male reference group $\left(20.5 v 25.8 \mathrm{~kg} / \mathrm{m}^{2} ; \mathrm{P}<0.001\right)$.

Maximum working capacity of runners on bicycle ergometry averaged $407(78 \cdot 3) \mathrm{W}$ (range 290 to $530 \mathrm{~W}$ ) or $6.2(0.9) \mathrm{W} / \mathrm{kg}$ (range 4.5 to $8 \mathrm{~W} / \mathrm{kg}$ ). Corresponding values for the local Swedish control group were 238 (72) W

Table 2 Echocardiographic data on elite runners

\begin{tabular}{|c|c|c|c|c|c|c|c|c|}
\hline Subject & $\begin{array}{l}\text { Heart rate } \\
\text { (beats } / \mathrm{min} \text { ) }\end{array}$ & $\begin{array}{l}\text { LVEDD } \\
(\mathrm{mm})\end{array}$ & $\begin{array}{l}\text { LVESD } \\
(\mathrm{mm})\end{array}$ & $\begin{array}{l}L A \\
(\mathrm{~mm})\end{array}$ & $\begin{array}{l}\text { Septum } \\
(\mathrm{mm})\end{array}$ & $\begin{array}{l}P W \\
(m m)\end{array}$ & $\begin{array}{l}L V M I \\
\left(\mathrm{~g} / \mathrm{m}^{2} B S A\right)\end{array}$ & $E / A$ ratio \\
\hline $\begin{array}{r}1 \\
2 \\
3 \\
4 \\
5 \\
6 \\
7 \\
8 \\
9 \\
10 \\
11 \\
12 \\
13 \\
14\end{array}$ & $\begin{array}{l}44 \\
65 \\
48 \\
52 \\
53 \\
45 \\
56 \\
47 \\
53 \\
48 \\
55 \\
62 \\
73 \\
64\end{array}$ & $\begin{array}{l}54 \\
54 \\
53 \\
54 \\
54 \\
56 \\
53 \\
58 \\
55 \\
47 \\
56 \\
53 \\
49 \\
55\end{array}$ & $\begin{array}{l}37 \\
40 \\
39 \\
39 \\
32 \\
37 \\
35 \\
38 \\
40 \\
30 \\
41 \\
36 \\
32 \\
34\end{array}$ & $\begin{array}{l}26 \\
34 \\
32 \\
33 \\
34 \\
38 \\
30 \\
31 \\
32 \\
35 \\
32 \\
28 \\
24 \\
37\end{array}$ & $\begin{array}{r}12 \\
9 \\
12 \\
11 \\
12 \\
12 \\
12 \\
10 \\
11 \\
9 \\
10 \\
11 \\
9 \\
11\end{array}$ & $\begin{array}{r}13 \\
10 \\
12 \\
11 \\
12 \\
12 \\
12 \\
8 \\
11 \\
11 \\
11 \\
11 \\
10 \\
12\end{array}$ & $\begin{array}{l}184 \\
122 \\
179 \\
166 \\
187 \\
192 \\
179 \\
142 \\
157 \\
125 \\
163 \\
156 \\
123 \\
175\end{array}$ & $\begin{array}{l}1.6 \\
1.8 \\
1.8 \\
2.1 \\
2.6 \\
2.9 \\
1.4 \\
2.9 \\
2.0 \\
2.2 \\
2.8 \\
1.7 \\
1.9 \\
1.7\end{array}$ \\
\hline $\begin{array}{l}\text { Mean } \\
\text { SD }\end{array}$ & $\begin{array}{c}55 \\
8 \cdot 3\end{array}$ & $\begin{array}{r}53.6 \\
2.7\end{array}$ & $\begin{array}{r}36 \cdot 4 \\
3 \cdot 3\end{array}$ & $\begin{array}{r}31.9 \\
3.8\end{array}$ & $\begin{array}{r}10 \cdot 8 \\
1.2\end{array}$ & $\begin{array}{r}11 \cdot 1 \\
1.2\end{array}$ & $\begin{array}{l}161 \\
23.4\end{array}$ & $\begin{array}{l}2 \cdot 1 \\
0.5\end{array}$ \\
\hline
\end{tabular}

LVEDD, left ventricular end diastolic dimension; LVESD, left ventricular end systolic dimension; LA, left atrial dimension Septum, interventricular septal thickness; $\mathrm{PW}$, left ventricular posterior wall thickness; LVMI, left ventricular mass index; $g / \mathrm{m}^{2}$ BSA, body surface area; E/A ratio, ratio of Doppler measured flows over the mitral valve during early versus late diastole. 
Stress

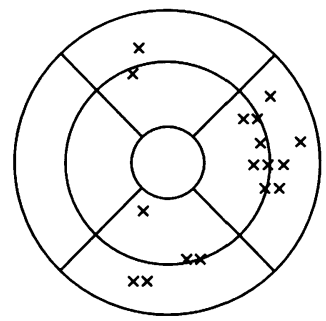

Rest

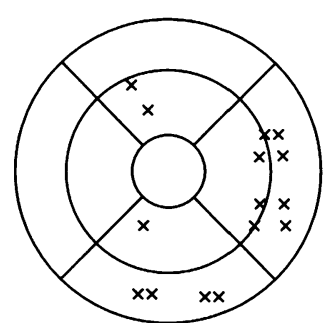

Figure 1 Localisation of uptake defects on bull's eye plots during stress and rest in 16 healthy male athletes compared with the local Swedish reference group.

Stress

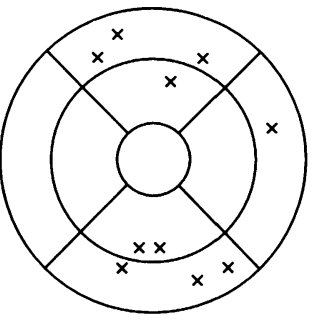

Rest

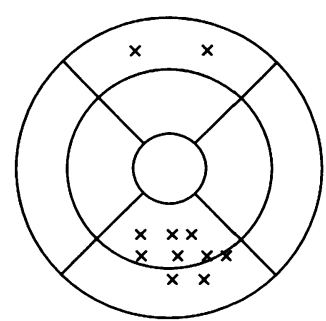

Figure 2 Localisation of uptake defects on bull's eye plots during stress and rest compared with the American reference group (Emory University Hospital). in 16 healthy male athletes (range 160 to $300 \mathrm{~W}$ ) or $3.3(0 \cdot 6) \mathrm{W} / \mathrm{kg}$ (range 1.9 to $4.1 \mathrm{~W} / \mathrm{kg})(\mathrm{P}<0.001)$. No arrhythmias or pathological ST changes were observed during the exercise test in either group. On echocardiographic examination (table 2) runners' mean end diastolic left ventricular dimensions and wall thickness were within normal limits $(53.6(2.7) \mathrm{mm}$, range 47 to $58 \mathrm{~mm}$, and $11(1.2) \mathrm{mm}$, range 9 to $13 \mathrm{~mm}$, respectively). Mean left ventricular mass index (LVMI) was about $8 \%$ above upper limits for healthy men $\left(161(23.4) \mathrm{g} / \mathrm{m}^{2} v 150 \mathrm{~g} / \mathrm{m}^{2}\right),{ }^{14}$ but the relation between wall thickness and left ventricular dimension was normal. ${ }^{15} 16$

Reconstruction and processing of polar maps showed significant uptake defects in most of the healthy runners examined in comparison with both the local Swedish and the American reference groups. Compared with the local Swedish control group, 13/16 runners had defects during stress and 11/16 during rest. A total of 32 defects was recorded during stress and rest (fig 1). When using the American reference group, 10/16 athletes had defects during stress and rest. A total of 21 defects was recorded during stress and rest (fig 2). Two subjects had reversible defects in the lateral region of the left ventricle. Average extent of stress defects was 26 (11) pixels and $20(4.6)$ pixels, average severity $3.5(0.7)$ $\mathrm{SD} /$ pixel and $3.4(0.6) \mathrm{SD} /$ pixel when comparing with the local Swedish and the American reference group, respectively.

Defects were located in the anterior, lateral, and inferior portion, while no defects were seen in the septal region of the left ventricle (figs 1 and 2). Reconstruction of polar maps with uniform attenuation correction according to Chang's principle resulted in a significant increase of defect size versus the American reference group both at rest $(25 v 53$ pixels, $\mathrm{P}<$ $0.05)$ and during stress (20 v 61 pixels, $\mathrm{P}<$ $0.01)$. The number of posterior defects decreased slightly, whereas anterior defects increased both in number and size with attenuation correction.

\section{Discussion}

In the present study healthy young runners showed a high incidence of myocardial uptake defects as measured by semiquantitative SPECT when comparing the polar plots both with a reference group of healthy males (local Swedish) studied with the same gamma camera equipment and with a commonly used American reference group. ${ }^{12}$

Semiquantitative methods for interpretation of myocardial SPECT with comparisons with healthy reference groups have been introduced to increase the diagnostic power and objectivity, especially in borderline cases, as compared to visual analysis of tomograms. As the purpose of the study was to test the applicability of semiquantitative SPECT for investigation of healthy well trained athletes we did not judge tomograms visually.

One explanation for the high frequency of uptake defects on polar maps could be cardiac disease. We did not perform coronary angio- graphy and therefore we cannot exclude the possibility of coronary artery disease. However, the pretest probability of coronary artery disease in the group examined is low. It also seems highly unlikely that the majority of a group of well trained athletes, without any cardiac history, competing on high national or international levels should suffer from ischaemic heart disease.

Differences in regional myocardial microcirculation in young well trained individuals compared to older and relatively less trained persons could, at least theoretically, explain the scintigraphic findings. However, no data confirming this hypothesis in normally trained persons or in animal studies seem to exist. On the contrary, resting myocardial blood flow in the left ventricle of healthy subjects is homogeneous as measured by PET. ${ }^{18}$ Animal studies using radiolabelled plastic microspheres show only minor systematic differences in blood flow to different regions of the left ventricle at rest and during exercise. ${ }^{19} 20$

Another explanation for the high incidence of uptake defects could be differences in body configuration between the runners in the present study and the reference material. The runners had significantly lower BMI compared with our male control group, which could result in different attenuation relations and different scintigraphic uptake patterns between the two groups. Application of a uniform attenuation algorithm enhanced rather than reduced uptake defects. This phenomenon could be due to the large variation of tissue densities within the thorax (bone, blood, fat, and air). Uniform attenuation correction according to Chang's principle is based on the occurrence of mainly homogeneous tissues and cannot adequately correct for the large variations of tissues and organs in the thoracic cavity. Recently developed methods for nonuniform attenuation correction using simultaneous transmission-emission scanning seem promising in order to reduce artefacts caused by differences in body configuration between subjects. ${ }^{21}$

In conclusion, our data show that if myocardial perfusion scintigraphy with the SPECT technique is used to evaluate well trained men, existing normal reference files for semiquantitative evaluation appear to be inadequate.

This study was supported by grants from the Swedish Board of Health and Welfare and by the Swedish National Centre for Research in Sports.

1 McCaffrey F, Braden D, Strong W. Sudden cardiac death in young athletes. Am $\mathcal{F}$ Dis Child 1991;145:177-83.

2 Maron B, Epstein S, Roberts W. Causes of sudden death in competitive athletes. $7 \mathrm{Am}$ Coll Cardiol 1986;7:204-14.

Zaret LB, Wackers FJ. Nuclear cardiology: review article. N Engl F Med 1993;329:775-83.

4 Meller J, Goldsmith SJ, Rudin A, Pickard AD, Gorlin R, Teichholz, et al. Spectrum of exercise thallium-201 myocardial perfusion imaging in patients with chest pain and normal coronary angiograms. Am $\mathcal{f}$ Cardiol 1979;43: 717-23.

5 Opherk D, Zebe H, Weihe E, Mall G, Durr C, Gravert B, et al. Reduced coronary dilatory capacity and ultrastructural changes of the myocardium in patients with angina pectoris but normal coronary angiograms. Circulation 1981;4:817-25.

6 Greenberg MA, Grose RM, Neuburger M, Silverman $R$ Strain RJ, Cohen MV. Impaired coronary vasodilator responsiveness as a cause of lactate production during pacing-induced ischemia in patients with angina pectoris . 年

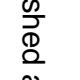 $\overrightarrow{0}$ . I

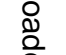 . $\overline{0}$ 골 . गे .

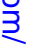
s) 
and normal coronary arteries. $\mathcal{F}$ Am Cardiol 1987;9: 743-51

7 Cannon R, Dilsizian V, O'Gara PT, Udelson JE, Schenke WH, Quyumi A, et al. Myocardial metabolic, hemodynamic, and electrocardiographic significance of reversible thallium-201 abnormalities in hypertrophic cardiomyopathy. Circulation 1991;83:1660-7.

8 Yen TC, Yeh SH. Marfan's syndrome with myocarditis demonstrated by $99 \mathrm{Tcm}-H M P A O-l a b e l l e d ~ W B C$ and 201-Thallium scintigraphy: report of three cases in a Chinese family. Nucl Med Commun 1993;14:712-6.

9 Satoh K, Utsumi J, Satoh H, Kasuya K. Evaluation of myocarditis using Th-201 myocardial scintigraphy with bull's eye functional map. Kokyo To funkan 1991;39: bull's eye

10 Muller S, Muller P, Meyer R, Volkmann H, Gottschild D, Thoss $\mathrm{K}$, et al. Myocardial bioptic findings in correlation with TL-201 imaging and hemodynamic parameters in patients with latent cardiomyopathies suspected of having myocarditis. Hearts Vessels 1985;1 (suppl):111-5.

11 Tamaki N, Yonekura Y, Kadota K, Kambara H, Torizuka $\mathrm{K}$. Thallium-201 perfusion imaging in myocarditis. Clin Nucl Med 1985;10:562-6.

12 De Puey EG, Garcia EV, Alasraki NF, Robbins WL, Folks RD. Comparison of Thallium-201 and Tc-99m MIBI for quantitative SPECT [abstract]. F Nucl Med 1988;29:793.

13 Diamond GA, Forrester JS. Analysis of probability as an aid in the clinical diagnosis of coronary-heart disease. $N$ Engl f Med 1979;300:1350-8.

14 Chang LT. A method for attenuation correction in radionuclide computed tomography. IEEE Trans Nucl Sci 1978;25:638-43.

15 Levy D, Savage DD, Garrison RJ, Andersson KM, Kannel WB, Castelli WP. Echocardiographic criteria for left ventricular hypertrophy: the Framingham study. $A m \mathcal{J}$
Cardiol 1987;59:956-60.

16 Maron BJ, Pelliccia A, Spirito P. Cardiac disease in young trained athletes. Insights into methods for distinguishing athletes heart from structural heart disease, with particular emphasis on hypertrophic cardiomyopathy. Circulation 1995;91:1596-601.

17 Gardin JM, Henry WL, Savage DD, Ware JH, Burn C Borer JS. Echocardiographic measurements in normal subjects: Evaluation of an adult population without clinicabjects: Evaluation of an adult population without clini439 .

18 Sambuceti G, Parodi O, Marcassa C, Neglia D, Salvadori $P$, Assuero $G$, et al. Alteration in regulation of myocardia blood flow in one-vessel coronary artery disease determined by positron emission tomography. Am f Cardiol 1993;72:538-43.

19 Ball RM, Bache RJ, Cobb RF, Greenfield JC. Regiona myocardial blood flow during graded treadmill exercis in the dog. $\mathcal{F}$ Clin Invest 1975;55:43-51.

20 Schlant RC. Anatomy of the heart. In: Hurst JW, et al, eds The heart, 6th ed. New York: McGraw-Hill, 1986:16-36.

21 Tan P, Bailey DL, Meikle SR, Eberl S, Fulton RR, Hutton BF. A scanning line source for simultaneous emission and transmission measurements in SPECT. $₹ \mathrm{Nucl}$ Med 1993;34:1752-60. 